İş ve İnsan Dergisi I The Journal of Human and Work

Y1l | Year: Nisan | April 2017

Cilt-Sayı | Volume-Issue: 4 (1)

ss I pp: $35-46$

doi: 10.18394/iid.287762

e-ISSN 2148-967X

http://dergipark.gov.tr/iid/

Araştırma Makalesi

\title{
Problemlerle Başa Çıkmak: Huzurevinde Çalışan Birim Yöneticileri İçin Vaka Tabanlı Çıkarsama Yaklaşımı
}

\author{
Dealing with Problems: A Case Based Reasoning Model for \\ Nursing Home Unit Supervisors
}

Serkan Erebak ${ }^{\mathbf{a}}$

\section{MAKALE BİLGİSI}

Anahtar Kelimeler:

Vaka tabanlı çıkarsama,

Problem çözme, Eğitim,

Huzurevi

\section{Tarihler :}

Gelis 24 Ocak 2017

Düzeltme geliş 03 Mart 2017

Kabul 03 Mart 2017

\section{ÖZ}

\begin{abstract}
Yaşlı nüfusunda gün geçtikçe yaşanan artış aynı zamanda huzurevleri gibi yaşlılara hizmet veren kuruluşların sayısının da artmasına sebep olmaktadır. Bu kuruluşlarda kalan yaşlılarla birlikte, bu kişilere hizmet veren çeșitli meslek dallarından çallşanlar da mevcuttur. Bu kurumda çalışan yönetici pozisyonundaki kişilerse hem kurum sakinlerinin problemlerinin çözülmesinden hem de kurumun çalıșma düzeninin sağlanmasından sorumludurlar. Bundan dolayı, bu çalışmada yaklaşık 800 sakine hizmet veren bir huzurevinin birim yöneticilerinin problem çözme becerilerinin geliştirilmesi amaçlanmıştır. Bu amaç doğrultusunda da vaka tabanlı öğrenme modeli kapsamında, yarı deneysel bir yöntem izlenerek 4 haftalık bir ĕgitim verilmiştir. Ön-test ve son-test uygulanan katılımclların nicel verilerinin sonuçlarına göre önemli bir fark bulunamazken, nitel veriler katılımcıların eğitimi faydalı bulduklarını göstermiştir. Sonuçlar, vaka tabanlı çıkarsama öğretilerinin bu tip kurumlarda oldukça kabul görebilecĕgini göstermiştir.
\end{abstract}

\footnotetext{
a Marmara Üniversitesi, Sosyal Bilimler Enstitüsü, İstanbul, Türkiye. serkan.erebak@ gmail.com.
} 


\section{GİRIŞ}

Yaşlı nüfusuna hizmet veren kuruluşların artmasıyla, bu sektörde çalışan sayısı da artmıştır. Gerek hizmet alan yaşlilar gerekse de hizmeti sağlayan çalışanlar düşünüldüğünde, her iki tarafin da memnuniyetini sağlayabilecek etkin ve verimli çözüm üretimleri, hizmette kaliteyi de yükseltecektir. $\mathrm{Bu}$ amaç doğrultusunda çalışanların problem çözme becerilerini geliştirmeleri için çeşitli eğitim modelleri araştırılmış ve uygulamaya da konulmuştur. Tecrübelerin yeni problemlerin çözümünde kullanılmasının önünü açan vaka tabanlı öğreti de bu modeller arasındadır. $\mathrm{Bu}$ modelin uygulamaları ise vakaların farklılığı dolayısıyla kurumdan kuruma değişebilmektedir. Ancak, huzurevlerine yönelik bu tip yaklaşıma sahip araştırmalar bilindiği kadarıyla pek yoktur. Bundan dolayı, bu çalışmada da huzurevinde yönetici olarak çalışanların problem çözme becerilerini geliştirmek için vaka tabanlı çıkarsama yöntemi aracı olarak kullanılmış ve bu yöntemin geliştirilmesine yönelik yeni uygulama faktörleri eklenmiştir.

\section{KURAMSAL ÇERÇEVE}

Vaka tabanlı öğrenme modeli uzun yıllardır uygulanan bir eğitim modelidir (Thistlethwaite vd.,
2012). İlk olarak James Lorrain Smith tarafindan patoloji öğretiminde vaka metodu olarak 1912 yılında tanıtılmıştır (Sturdy, 2007). Smith'e göre öğrenciler, hastalarında bulunan hastalık belirtilerini incelerken, geçmişteki hastalarının klinik geçmişini kullanırlarsa oldukça verimli sonuçlar elde edebilirlerdi. Yakın tarihlerde dünyanın önde gelen bazı üniversiteleri de (örn: Harvard Üniversitesi) vaka tabanlı öğrenme metodolojisini kullanmaya başlamıştır (Thistlethwaite vd., 2012). Giderek yaygınlaşan vaka tabanlı çıkarsamayı kullanan bu öğrenme modeli hem üniversitelerde hem de hizmet sektöründen çeşitli işletmelerde uygulamaya konmaktadır.

Vaka tabanlı çıkarsama nasıl kurulur? Öncelikle belirtmek gerekir ki, vaka tabanlı düşünme biçimindeki "vaka" çoğunlukla "problemin olduğu durumu" ifade etmek için kullanılır (Aamodt \& Plaza, 1994). Geçmişteki benzer durumlar hatırlanır ve hatırlanan bu durumlardan elde edilmiş bilgiler tekrar kullanılarak yeni bir problem çözülür. Vaka tabanlı çıkarsama biçiminde, bir problem hakkında genel olarak düşünmek veya problemlerin genel özellikleri arasında bağlantılar kurmak yerine, önceden tecrübe edilmiş bir problem çözme sürecine dair elde edilmiş bilgiler kullanılmaktadır (Aamodt \& Plaza, 1994). Yani, yeni bir problemi çözmek için geçmişte yaşanmış benzer bir durum ele alınır ve bu amaç doğrultusunda kullanılır. Sonuçta, vaka tabanlı çıkarsama biçiminde temel olarak bazı yollar izlenmektedir (bkz. Şekil-1). En

Şekil 1. Vaka Tabanll Çıkarsama Döngüsü (Aamodt \& Plaza, 1994)

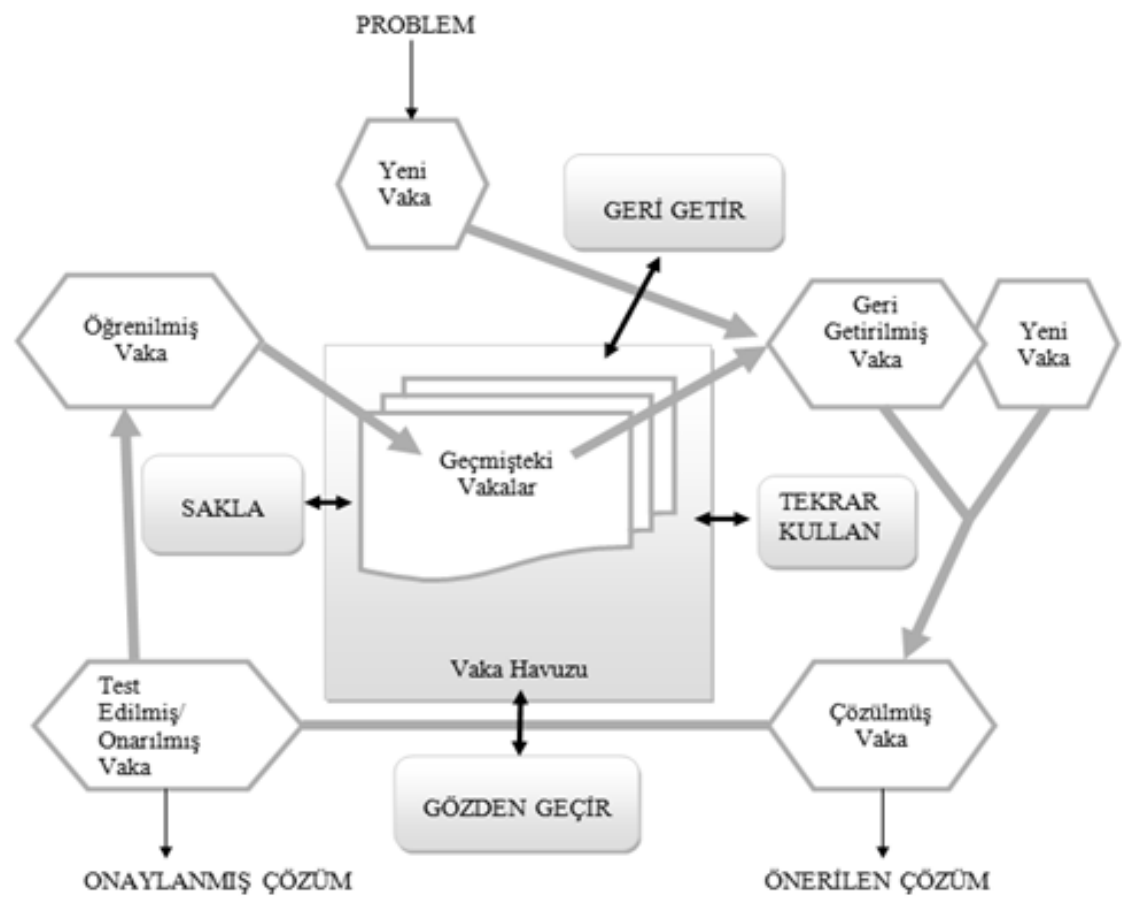


başta yeni problemin ne olduğu belirlenir. İkinci olarak, bu yeni probleme dair eskiden yaşanmış benzer bir durum bulunur. Eski durumdan yola çıkarak yeni problemin nasıl çözüleceğine dair çözüm yöntemi geliştirilir. Bu geliştirilen yöntem değerlendirilmeye alınır ve vaka tabanlı çözüm yöntemlerinin toplandığı havuza yenisi eklenir.

Vaka tabanlı çıkarsamanın kalitesi dört nokta ile yakından bağlantılıdır. Bunlar geçmişteki tecrübeler, yeni durumun eski tecrübeler 1şığında anlayabilme yetisi, uyarlama ve değerlendirme yaparken sahip olunan uzmanlıktır (Kolodner, 1992). Geçmişte ne kadar tecrübe kazanılmışsa kişinin vaka havuzu daha büyük olacaktır. Bu da çıkarsama yapacağı zaman daha büyük bir kaynaktan yararlanacağı anlamına gelir. Ancak yine de, daha çok tecrübesi olan kişinin daha az tecrübesi olan kişiye göre daha iyi cevaplar bulmasının bir garantisi yoktur (Kolodner, 1992). Çünkü bu durum kişinin daha çok olayın içeriğini ve yeni probleme nasıl uyarlayacağını kavramasıyla alakalı da olabilir. Yine de, yeni problemi çözmek için geçmişteki bir vakayı geri getirme vaka tabanlı çıkarsama sürecinin temelini oluşturmaktadır.

Tekrar kullanma sürecinde yeni durum eski deneyimlerle karşılaştırılır. Benzer ve zıt yönleri ortaya çıkartılır. Böylece yeni durum daha iyi tanımlanmış ve anlamlandırılmış olur. $\mathrm{Bu}$ da çıkarsama yapan kişinin izlenecek çözüm yolunun olumlu ve olumsuz etkileriyle tartmasına yardımcı olur. $\mathrm{Bu}$ aşama karşılaşılan problemin iyi şekilde kavranabilmesi için önemli bir adımdır. Gözden geçirme sürecinde ise uyarlama ön plandadır. Buradaki amaç geçmişteki vakanın çözümünün yeni vakanın çözümünün gerektirdiklerine adapte etmektir. Bunun yanında bulunan çözümün değerlendirilmesi ve geri bildirimlerin yapılması da sonraki çıkarsama süreçlerine yardımcı olmaktadır.

Vaka tabanlı çıkarsama yöntemini uygulayan bir huzurevi yöneticisi, huzurevinde aynı odada kalan sakinlerin TV izleme vakti konusundaki anlaşmazlıklarını, önceden buna benzer olayları nasıl çözdüğünü hatırlayarak ve önceki tecrübeleri kullanarak çözebilir. Bu örnekte de görüldüğü üzere, bu çıkarsama biçimine iş hayatında, özellikle huzurevlerinde sıkça karşılaşılabilir. Örneğin, huzurevinde çalışan bir doktor, benzer hastalık belirtilerini gördüğü yaşlı hastaya eskiden başka birine uyguladığı benzer bir tedavi yöntemi kullanarak yardımcı olabilir. Bu durumda da doktor vaka tabanlı düşünme biçimini uygulamış olur. Benzer şekilde, bir hasta bakıc1, Alzheimer ve benzeri hastalığı olan huzurevi sakininin banyoyu reddetmesi durumunu, geçmişteki yaşadığı benzer durumları hatırlayarak ve hatırladığı yöntemi bu hastaya uyarlayıp uygulayarak çözebilir. Verilen örneklerden de tahmin edilebileceği üzere, problem çözümünde geçmiş olayların kullanılması oldukça etkin ve sık uygulanabilen bir yöntemdir.

Anderson'a (1993) göre, bir amaç uğruna bir dizi bilişsel işlemler yürütmeye problem çözme denir. Ancak, burada problemin iyi bir şekilde anlaşılması gerekmektedir. Problem kavramının tanımlanmasında genellikle iki bakış öne çıkmaktadır (Jonassen, 2000). Bunlardan biri içinde bulunulan durum ile olmak istenen durum arasındaki farkı problem olarak tanımlamaktadır. Bu bir matematik problemi ya da sosyal bir problem olabilir. İkincisi ise, bilinmeyenin bulunması veya çözülmesinin sosyal, kültürel veya entelektüel bir değerinin olması gerekliliğidir. Yani birinin bahsi olan bilinmeyenin bulunması gerektiğini önemsemesi gerekiyor. Çünkü eğer kimse bir bilinmeyeni algılamazsa veya bilinmeyeni ortaya çıkarmak için bir ihtiyaç duymazsa algılanan bir problem yok demektir. Elbette, hiçbir algı olmadan da bir problem var olabilir, ancak bu durum bu çalışmanın dışında tutulmuştur. Sonuç olarak bu bilinmeyeni bulma sürecine ise problem çözme süreci denir.

Vaka tabanlı öğrenme biçimi genellikle problem tabanlı öğrenme biçimiyle karşılaştırılmaktadır; ancak bu iki metot arasındaki fark çok net değildir (Thistlethwaite vd., 2012). Bir görüşe göre, problem tabanlı öğrenme metodunda, bir problemin çözüm sürecinin kavranmasıyla öğrenme gerçekleşir (Barrows \& Tamblyn, 1980). Yani öğrenme sürecinde kişilere ilk olarak problem gösterilir. Ancak vaka tabanlı öğrenme metodu ise rehber eşliğinde yürütülen bir soruşturmadır, ne öğrenileceği bellidir ve problem tabanlı öğrenme metoduna göre daha yapılandırılmış şekildedir (Srinivasan, Wilkes, Stevenson, Nguyen \& Slavin, 2007). Örneğin, vaka tabanlı çıkarsamanın iki yöntemi mevcuttur (Kolodner, 1992). Bunlarda ilki olan problem çözme yönteminde, yeni vakalara çözüm aranırken eski vakaların çözümleri bir rehber olarak kullanılır. Böylece hem çözümler görülmüş olur hem de olası bir hatadan kaçınılmış olur. Diğer yöntem olan yorumlayıcı yaklaşımda, yeni vakalar geçmişteki vakalar şartlarında değerlendirilir. Yani mesela, bir avukat öne sürdüğü iddiayı desteklemek için geçmişteki vakaları kullanarak vaka tabanlı çıkarsamaya yorumlayıcı yaklaşmaktadır (Kolodner, 1992). İki yöntemde de, vaka havuzuna biriktirilen vakalar yeri geldiği zaman kullanılmak üzere ortaya çıkarılır ve çözümlenen vakalar bu depoya eklenir. Problem çözme yönteminde çözüm üretmek için ağırlıklı olarak yeni vakanın eski vakaya uyarlanması kullanılmaktadır. Ancak, üretilen çözümü değerlendirirken kesin bir yöntem yoksa veya belirsizlik mevcutsa, bulunan çözümü gerekçelendirmek için yorumlayıcı yöntem kullanılır. 
Hakkarainen, Saarelainen ve Ruokamo'ya göre (2007) vaka tabanlı öğrenme iş hayatı ve bilgilenme arasında bir köprü görevi görmektedir. Aynı şekilde, tartışma ve aktif katılım ortamını teşvik etmektedir (Hansen \& Krackov, 1994). Bu modelde, kişiler problem çözme sürecinde hem akranlarından hem de uzmanlardan destek alma firsat1 bulurlar (Sutyak, Lebeau, Spotnitz, O'Donnell \& Mehne, 1996), işbirlikçi öğrenmeyi (Stewart \& Gonzales, 2006) ve grup çalışmasını (Rybarczyk, Baines, McAndy, Thompson \& Wilkins, 2007) ön plana çıkarabilirler. Ayrıca bu yöntemde, sürekli şekilde yeni problemlerin tecrübe edilmesi ve çözülmesiyle, bir çeşit vaka havuzu oluşmaktadır, bu birikimle gelecekte karşılaşılacak problemler daha hızlı çözülebilmektedir (Aamodt \& Plaza, 1994). Geçmiş vakanın 1şığında yeni problemin çözülmesinin diğer bir faydası ise geçmişte yapılan hatalardan kaçınılması ve daha uygun çözüm önerileri getirilmesidir (Kolodner, 1992).

Yapılan çalışmalarda elde edilen geri bildirimlere göre katılımcılar oldukça olumlu sonuçlar elde etmişlerdir. Bunlar arasında, kendine olan güvenin artmas1 (DeMarco, Hayward \& Lynch, 2002), derinlemesine öğrenme anlayışının benimsenmesi (Schwartz, Egan \& Heath, 1994), öğrenmenin artmas1 (Street vd., 2007) yer almaktadır; ayrica, katılımcılar benzeri eğitimlere daha fazla katılmak istemişlerdir (Anderson \& Helberg, 2007). Geleneksel sunum yöntemlerinin aksine daha çok tercih edilen (Struck \& Teasdale, 2008) vaka tabanlı öğrenmenin katılımcılar tarafindan bağımsız ve eleştirel düşünmeyi arttırdığı belirtilmiştir (Krockenberger, Bosward \& Canfield, 2007). Bunun yanında, grup tartışmaları sayesinde katılımcılar arasındaki iletişim ve etkileşim de gelişmektedir (Chan, Hsu \& Hong, 2008). Mayo'ya göre (2002), vaka tabanlı öğrenme pratik çıkarsama becerilerinin gelişmesine oldukça yardımcı olmaktadır. Zaten, insanlar genel olarak karşılaştığ problemleri çözerken geçmiş durumları model alırlar, özellikle öğrenmenin ilk dönemlerinde bu sıkça kullanılmaktadır (Anderson, 1993). Vaka tabanlı çıkarsama biçiminde geçmiş tecrübelerden bir şeyler öğrenmek oldukça belirgin bir amaçtır; çünkü bu düşünce biçimine göre eskiden yaşanmış bir durumun çözümünü hatırlayıp yeni problemin çözümünde uygulamak, problem kavramı üzerinden yola çıkıp genellemeler yoluyla çözüme ulaşmaktan daha kolaydır. Bunun yanında, özellikle insanların birbirleriyle sosyal etkileşim içinde bulunduğu, işbirliği içerisinde problemleri çözdüğü öğrenme ortamı etkili olmaktadır (Dochy, Segers, Van den Bossche, \& Gijbels, 2003).

Gagne'ye (1980) göre eğitimin en önemli noktas1 insanlara düşünmeyi ve mantıklarını kullanmayı öğreterek daha etkili problem çözebilen insanlar olmasını sağlamaktır. Bunun yanında, yetişkinler özerk bireylerdir ve öğrenme süreçlerinde öğretmenlerin daha çok bu sürecin kolaylaşmasına yardım eden kişiler olması gerekmektedir (Holton \& Swanson, 1998). Problem çözme sürecinin etkenlerinden bir tanesi de işbirliğidir (Barrows, 1994). Hornby'e (2000) göre işbirliği bir grupta birkaç kişinin beraber işin içine girmesidir. İşbirliğinin kullanıldığı öğrenme süreçlerinde bireysel öğrenmeler yükselmektedir (Thorley, Gregory, \& Gregory, 1994). Çünkü fikirlerin değiş tokuş edilmesiyle, işlenen konular daha iyi anlaşılmaktadır.

Huzurevlerinin yöneticileri ve çalışanlarının eğitilmesi özellikle bu kurumlarda kalan yaşlıların bakımının kaliteli olarak sürdürülmesi için çok önemlidir (Domke \& Murphy, 1959). Bu personellerin iyi şekilde koordine olması, çatışma çözümü yöntemlerine hakim olması gibi özelliklere sahip olması bakım kalitesini yüksek derecede etkilemektedir (Flood, Zinn, Shortell, \& Scott, 2000; Miller \& Luft, 1994; Flood, 1994). Bunun yanında huzurevi yöneticilerinin kurumda yaşlılara sağlanan hizmetler üstünde önemli ölçüde etki payı mevcuttur (Hofmann, 1977).

Huzurevleri gibi sakin memnuniyetinin sağlandığı, çeşitli mesleklerden insanların görev yaptığı, gönüllülerin ve genel ziyaretçilerin sıkça bulunduğu kuruluşlarda farklı konularda birçok problemle karşılaşılmaktadır. Problemler çözülürken kurumda kalan sakinlerin yararlanması ve kurumda çalışan personelin de çalışma ortamının iyiliği hesaba katılmak zorundadır. Bunlar göz önüne alındığında bu kuruluşlarda görev yapan yöneticilerin yöneticilik becerilerinin çeşitlendirilmesi ve geliştirilmesi oldukça önem arz etmektedir. Yukarıda da belirtildiği gibi verilen hizmetin kalitesi bu becerilerle yakından alakalıdır. Bundan dolayı, çeşitli çalışmalarca etkililiği ve verimliliği kanıtlanmış olan vaka tabanlı çıkarsama eğitimlerinin, bu tip kurumlarda karşılaşılabilecek farklı problemlerin çözümünde etkin olacağı düşünülmektedir.

$\mathrm{Bu}$ çalışmanın temelinde, her problemin aynı olmadığı ve aynı yolu izleyerek çözülemeyeceği varsayımı yer almaktadır. Bundan dolayı vaka tabanlı öğrenme modeli uygulanmak istenmiştir. $\mathrm{Bu}$ model aracılığıyla katılımcıların huzurevinde gerçekleşmiş vakalara daha çok aşina olmalarının ve bu vakaların farklı bakış açılarına sunulmasının katılımcıların problem çözme becerilerine etki edeceği düşünülmektedir. Böylece, vaka tabanlı çıkarsamanın problem çözme yöntemi kullanılarak, yeni vakalara çözüm aranırken eski vakaların çözümleri bir rehber olarak kullanılırsa 
katılımcıların problem çözme becerileri geliştirilmiş olur. Bundan dolayı şu hipotez kurulmuştur:

Hipotez: Vaka tabanlı çıkarsama eğitimi huzurevi yöneticilerinin problem çözme becerisini arttırmaktadır.

\section{ARASTIRMANIN YÖNTEMI}

\section{1. Örneklem}

Araştırmanın katılımcıları İstanbul'daki yaklașık 800 yaşlıya hizmet veren en büyük huzurevlerinden birinde çalışan 26 birim sorumlusundan oluşmaktadır. $\mathrm{Bu}$ huzurevi, kampusu içinde yaşlıların gereksinimlerine ve cinsiyetlerine göre ayrılmış 10 siteden ve ek olarak kendisine bağlı kampus dișında da 2 siteden, yani toplam da 12 siteden oluşmaktadır. Ayrıca huzurevinin bünyesinde İstanbul'un çeşitli semtlerine yayılmış yaşlıların kaldığı iki kişilik 25 ev mevcuttur. Bunun dişında genel olarak bu birimlere hizmet eden manevi destek, sosyal servis, teknik işler, bilgi işlem, yemekhane işleri ve benzeri gibi birimler de mevcuttur. Siteler ve diğer birimlerin her birinin tek sorumlusu vardir. $\mathrm{Bu}$ sorumlular da Huzurevi müdürüne bağlıdırlar. Katılımcıların yarısını site sorumluları (13 kişi), diğer yarısını ise diğer birimlerin sorumluları (13 kişi) oluşturmaktadır. Katılımcilar cinsiyetlerine göre ise 10 kadın (\% 39), 16 erkek $\left(\begin{array}{ll}\% & 61\end{array}\right)$ olarak dağılmaktadır. Katılımcıların her biri yüksekokul veya üstü eğitim seviyesine sahiptirler.

\subsection{Prosedür}

Vaka tabanlı çıkarsama eğitimi için bir ön-test ve bir son-testten oluşan yarı deneysel yöntem kullanılmıştır. Çalışma öncesinde katılımcıların problem çözme becerilerini ölçen bir test kullanılmıştır. Çalışma sonrasında ise tekrar katılımcıların problem çözme becerilerini ölçen bir test ve çalışmanın kendisine dair görüşlerinin sorulduğu niteliksel ve niceliksel bir anket uygulanmıştır. Ancak bu çalışmada bir kontrol grubu olmadığ 1 için iç geçerliliği azaltabilecek olası tarih, olgunlaşma ve test etkisi kontrol edilememiştir.

Eğitim başlamadan katılımcılar, her biri 6 site sorumlusu ve 6 da diğer sorumludan oluşmak üzere iki gruba ayrılmış ve bu gruplara kontenjanları dolduracak şekilde rastgele dağılım yapılmıştır. Kalan bir site sorumlusu ve bir diğer birim sorumlusu da aynı şekilde rastgele gruplara yerleştirilmiştir. Ancak eğitim süresince yıllık izin, acil müdahalesi gereken işler, hastalık ve benzeri sebeplerden dolayı tam katılım sağlanamamış, toplamda 16 kişilik (7 kişi site sorumlusu, 9 kişi diğer sorumlular) bir katılımc1 grubuyla (1. Grup 7 kişi, 2. Grup 9 kişi) ile eğitim tamamlanmıştır.

İlk hafta belirlenen saatte tüm katılımcılar eğitimin verileceği toplantı odasına toplanmıştır. İlk önce tüm katılımcılara problem çözme becerilerini ölçen bir test uygulanmıştır. Ardından eğitici tarafından eğitimin içeriği ve seansların yapılandırılmış süreci anlatılmış (bknz. Tablo 1) ve sorular cevaplanmıştır. Katılımcılara ait oldukları gruplar bildirilmiștir. Katılımcılara geçmişte tecrübe ettikleri bir vakayı hatırlamalarını ve bu vakanın çözümüyle birlikte anlattıkları bir yazıyı eğitimciye

Tablo 1. Eğitim Seanslarının Yapılandırılmış Süreci

1. Kat1limc1lar eğiticiye vakaları gönderir.

2. Eğitici vakaları eğitime uygunluğuna ve konularına göre değerlendirir, sınıflandırır.

3. Seçilen vakalar katılımcılar tarafindan çözümleri dile getirilmeden hikâye şeklinde sunulur.

4. Katılımc1lar kendi aralarında vakayı tüm yönleriyle tartışır ve çözümlerini dile getirir

5. Vakay1 sunan kat1lımcı kendi çözümünü ifade eder.

6. Tüm çözümler değerlendirilir ve genel kabul gören çözümün vaka tabanlı ç1karsamaya uygun olarak analizi yapilır, çözüm sürecindeki basamaklar eğitici tarafindan anlatılır.

7. Vaka ve çözümü vaka havuzuna eklenir. 
1 hafta içinde mail atmaları söylenmiştir. Ayrıca her hafta eğitimci tarafından seçilecek iki kişinin eğitimciye yazılı olarak gönderdiği vakası hakkında kısa bir sunum yapacağı belirtilmiştir. Böylece, her bir katılımcının eski vakası diğer katılımcılara yeni vaka olarak sunulmuştur. Yeni vakalara çözüm aranırken de eski vakaların çözümleri bir rehber olarak kullanılmıştır. Yani, vaka tabanlı çıkarsama modelinin problem çözme yöntemi uygulanmıştır.

Tanıtım haftasından eğitimin başlayacağı sonraki hafta arasında eğitimciye gönderilen vakalar eğitimci tarafından değerlendirilmiş ve vakalar personelle ilgili, huzurevi sakinleriyle ilgili ve diğer konular olmak üzere 3 başlığa ayrılmıştır. Tanıtım haftası haricinde 4 hafta 1 'er saat ardışık seanslarla sürecek olan eğitimin ilk haftası personellerle ilgili vakalara, ikinci haftası sakinlerle ilgili vakalara, üçüncü haftası ise diğer vakalara ayrılmıştır. Son hafta ise vaka tabanlı çıkarsamayla alakalı genel olarak değerlendirmeler yapılmış, problem çözme becerilerini ölçen bir test uygulanmış; ayrıca, eğitim hakkındaki değerlendirmelerinin sorulduğu bir anket doldurulmuştur. Her bir seansta eğitimci tarafindan uygun bulunan vakanın (bir problemi ve çözümü olan, başka vakalara uyarlanabilme potansiyeli mevcut olan) kisaca sunumu (nasil çözüm getirildiği bahsedilmeden) gerçekleştirilmiştir. Sonra katılımcılara kendi tecrübelerinden yola çıkarak benzer vakaları özellikleriyle birlikte hatırlamalarını ve sunulan vakayı kendi tecrübe ettiği vakalar 1şı̆̆ında nasıl çözebileceğini düşünmeleri istenmiştir. Ardından, katılımcılar ikili gruplar halinde kendi analizlerini başka bir katılımcıyla paylaşmış, yine ardından sırayla tüm katılımcılar bütün grupla kendi uyarlamasını paylaşmıştır. Sonrasında, sunumu yapan kişi kendi çözüm yolunu anlatmıştır. En sonunda ise, katılımcılar kendi aralarında çözümler hakkında değerlendirmelerde bulunmuşlardır. Her bir sunum ve tartışma süreci toplamda yaklaşık 30 dakika sürmüştür. Vaka tabanlı çıkarsama yöntemleri ise eğitimci tarafından vakanın genel tartışması sırasında vaka üzerinden kısaca anlatılmış, katılımcılar bu konuda yönlendirilmiştir.

Genel olarak, problem tabanlı öğrenme modelinde uyulması gereken kuralların (Barrows, 1994) birçoğu vaka tabanlı çıkarsama konulu bu eğitimde de uygulanmıştır. Öncelikle, öğrenme ortamının katılımc1 merkezli olması; yani, klasikleşen, öğreticinin konuyu anlattığı katılımcıların ise pasif olarak dinlediği bir öğrenme ortamının aksine katılımcıların konuyu anlamlandırıp tartıştığı bir oturum düzenlenmiştir. İkinci olarak oturumlarda etkili ve verimli bir tartışma ortamının sağlanabilmesi için katılımcı sayısı düşük tutulmuştur. Üçüncüsü, öğretici pozisyonundaki kişi daha çok oturumu yönlendirici bir yaklaşım sergilemiştir. Dördüncü olarak, vakalar problem çözme becerilerinin geliştirilmesi için bir araç olarak kullanılmıştır.

\section{3. Ölçekler}

Problem Çözme Becerileri Ölçeği. Kişinin kendi problem çözme becerisine dair algısını ölçen bu ölçek Heppner ve Peterson (1982) tarafindan geliştirilmiş ve iç tutarlılık katsayısı .90 olarak bulunmuş; sonrasında ise Şahin, Şahin ve Heppner (1993) tarafindan Türkçe sürümü oluşturulmuştur. $\mathrm{Bu}$ ölçek toplamda 35 maddeden oluşmaktadır. Her bir madde kesinlikle kat1liyorum (1 puan) ve kesinlikle katılmıyorum (6 puan) iki ucu arasında Likert tipi ölçekle değerlendirilmektedir. Ölçeğin problem çözmede kendine güvenme (problem solving confidence), girişimci-kaçınmacı stil (approach avoidance style) ve kişisel kontrol (personal control) başlıklarında 3 alt boyutu mevcuttur. Testin Türkçe sürümüyle yapılan bir araştırma da ise iç tutarlılık katsayısı .79 olarak bulunmuştur (Karataş, 2011). Bu çalışmada ise testin iç tutarlılık katsayısı .848 çıkmıştır. İç tutarlılığı düşüren 2 madde çıkarılmıştır. Çalışma da testten alınabilecek en düşük puan 33 en yüksek puan ise 198'dir. Orijinal ölçekte puanların yüksekliği katılımcının problem çözme becerisinin düşüklüğüne işaret etmektedir. Ancak bu çalışmada, madde puanları tersine kodlanmıştır, dolayısıyla yüksek puanlar kişinin problem çözme becerisinin yüksekliğini göstermektedir.

Geri Bildirim. Katılımcıların eğitim hakkındaki görüşleri ise hiç (1 puan) ve çok (6 puan) iki ucu arasında Likert tipi değerlendirmenin yapıldığg 4 soru ve eğitimin faydalı ve geliştirilmesi gereken yönlerinin sorulduğu açık uçlu 2 soruyla edinilmiştir.

\subsection{Veri Analizi}

Araştırma verilerinin analizlerinde SPSS 21.0 paket programı kullanılmıştır. Ön test ve son testler arasındaki farkı anlamak için bağımlı grup t testi analizi kullanılmıştır. Geri bildirimler ise tanımlayıcı istatistik ile incelenmiştir. Yapılan Kruskal-Wallis testinde grupların normal dağıldığı bulunmuştur.

\section{BULGULAR VE SONUÇ}

\subsection{Problem Çözme Becerileri}

Vaka tabanlı çıkarsama eğitimi alan 16 katılımcının problem çözme becerilerindeki değişim bağıml grup $\mathrm{t}$ testi yöntemiyle ölçülmüştür. Öncellikle, 
Tablo 2. Ön-Test Son-Test Farkll1ı̆̆nı gösteren Bağımlı Grup T Testi Sonuçları

\begin{tabular}{|c|c|c|c|c|c|c|}
\hline \multirow[t]{2}{*}{ Ölçümler } & \multicolumn{2}{|c|}{ Ön-Test } & \multicolumn{2}{|c|}{ Son-Test } & \multicolumn{2}{|c|}{$\begin{array}{c}\text { Bağml Grup T } \\
\text { Testi }\end{array}$} \\
\hline & Ort. & S.S. & Ort. & S.S. & $\mathbf{t}$ & $\mathbf{p}$ \\
\hline $\begin{array}{l}\text { Problem Çözme } \\
\text { Becerisi }\end{array}$ & 155.69 & 11.49 & 154.25 & 19.21 & .242 & .812 \\
\hline $\begin{array}{l}\text { Problem Çözmede } \\
\text { Kendine Güven }\end{array}$ & 46.44 & 2.55 & 44.19 & 7.32 & 1.164 & .263 \\
\hline $\begin{array}{l}\text { Girişimci- } \\
\text { Kaçmmacı Stil }\end{array}$ & 71.50 & 10.47 & 73.31 & 9.99 & -.498 & .626 \\
\hline Kișisel Kontrol & 24.69 & 2.18 & 23.00 & 3.86 & 1.861 & .083 \\
\hline
\end{tabular}

testten elde edilen ön-test ve son-test toplam puanları karşılaştırılmıştır. Sonrada, testin 3 alt boyutu arasındaki ön-test ve son-test farklılıkları incelenmiştir. Tablo 2'de görüleceği üzere eğitimi tamamlayan katılımcıların hem problem çözme becerilerindeki toplam puanda, hem de testin alt boyutları olan problem çözmede kendine güvenme, girişimci-kaçınmacı stil ve kişisel kontrolde herhangi bir fark bulunamamıştır. $\mathrm{Bu}$ sonuçtan dolayı bu çalışmada kurulan hipotez reddedilmiştir.

Tablo 3. Geri Bildirimden Elde Edilen Nicel Veriler

\begin{tabular}{|c|c|c|c|c|c|c|c|c|}
\hline \multirow[b]{5}{*}{ Yantlar } & \multicolumn{2}{|c|}{$D^{2}$} & 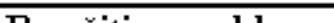 & hlem & \multicolumn{2}{|c|}{ Sizce bu eŏitim de } & \multicolumn{2}{|c|}{ Bu eğitimi } \\
\hline & \multicolumn{2}{|l|}{ kadar } & \multicolumn{2}{|c|}{ çözümüne bakıs } & \multicolumn{2}{|c|}{ kazanllanlar } & \multicolumn{2}{|l|}{ baska } \\
\hline & \multicolumn{2}{|c|}{ kullanıșlı } & \multicolumn{2}{|c|}{ açmuza herhangi bir } & \multicolumn{2}{|c|}{ pratikte } & \multicolumn{2}{|c|}{ sorumlulara } \\
\hline & buldur & & katkı sa & $\mathrm{mi}$ ? & uygula & bilir mi? & önerir & Misiniz? \\
\hline & Siklik & Yüzde & S1klik & Yüzde & S1klik & Yüzde & S1klik & Yüzde \\
\hline 1 (hiç) & 0 & 0 & 0 & 0 & 0 & 0 & 0 & 0 \\
\hline 2 & 0 & 0 & 1 & 6.25 & 0 & 0 & 0 & 0 \\
\hline 3 & 1 & 6.25 & 1 & 6.25 & 2 & 12.5 & 1 & 6.25 \\
\hline 4 & 5 & 31.25 & 8 & 50 & 3 & 18.75 & 5 & 31.25 \\
\hline 5 & 6 & 37.5 & 3 & 18.75 & 7 & 43.75 & 5 & 31.25 \\
\hline 6 (çok) & 4 & 25 & 3 & 18.75 & 5 & 31.25 & 5 & 31.25 \\
\hline Toplam & 16 & 100 & 16 & 100 & 16 & 100 & 16 & 100 \\
\hline
\end{tabular}


$\mathrm{Bu}$ sonuçlara göre eğitime katılan 16 katılımcının problem çözme beceri düzeyleri eğitimin öncesinden sonrasına kadar önemli farklılık göstermemiştir.

\subsection{Katılımcıların Değerlendirmeleri}

Eğitim son seansında katılımcılar son-testi doldurduktan sonra geri bildirimde bulunmaları için yeni bir form doldurmuşlardır. Bu formlardan elde edilen veriler tanımlayıcı istatistik yöntemiyle Tablo 3'te sunulmuştur.

$\mathrm{Bu}$ sonuçlar genel olarak incelendiğinde, katılımcıların vaka tabanlı çıkarsama öğrenme modelinden memnun oldukları çıkarılabilir. Katılımcıların yaklaşık yüzde 90'ı eğitimi kullanışlı bulmuş, eğitimin problem çözümüne bakış açısına katkı sağladığını belirtmiş, pratikte de uygulanabilecek edinimleri olduğunu ve başka meslektaşlarına bu eğitimi önereceğini belirtmiştir.

Eğitimin son seansında katılımcıların değerlendirmelerini daha iyi anlamak için katılımcıların eğitimde faydalı buldukları ve eğitim kapsamında geliştirilmesini düşündükleri noktaları belirtecekleri yapılandırılmış açık uçlu iki soru verilmiştir. Eğitimin faydalı yönlerine dair verilen yanıtlar incelendiğinde, katılımcıların çoğunlukla vakaların farklı bakış açılarıyla çözülebileceğine ve grup çalışmasının yarattığ verimliliğine dair farkındalık yaşadıkları anlaşılmaktadır. Eğitimin geliştirilmesi gereken yönlerine dair ise en çok katılımcıların devamlılığının sağlanabilmesi konusunda geri bildirim alınmıştır. Ayrıca vakaların çözülme biçimlerinin daha da teknik hale getirilmesi önerilmiştir. Tablo 4'te katılımcıların açık uçlu sorulara verdiği cevaplardan örnekler bulunmaktadir.

Genel olarak katılımcılardan elde edilen bu geri bildirimler, vaka tabanlı çıkarsama yöntemlerinin olumlu karşılandığı ve verimli olarak algılandığ yönündedir. Katılımcıların büyük çoğunluğu bu eğitimi kullanışlı, pratiğe uygun, bakış açısını genişleten ve diğer meslektaşlara önerilebilecek şekilde değerlendirmiştir. Bunun yanında, eğitim süresince gerçek olaylardan yola çıkarak tartışma ortamının sağlanmış olduğu farklı bakış açılarını görme durumu katılımcılar tarafindan oldukça faydalı bulunmuştur.

Tablo 4. Geri Bildirimden Elde Edilen Nitel Veriler

Eğitimin size göre en faydalı yönü neydi?

"Problemleri çözmede farklı çözümlerin de olabileceğini öğrendim. Bana göre doğru olan çözümün başkasına göre yanllş olabileceğini daha net anladım." (4)

"Problemleri çözerken isti̧̧arenin önemini dahaiyi kavradım." (3)

"Bana özgü olarak düşündügüm problemlerin benzerini başkalarının da yaşadığının farkına vardım. Aynca onların bu olaylara bakış açısını görmek güzel oldu." (2)

"Çalışma arkadaşlarımla bir araya gelip onları dahaiyi tanıdım, haklarında biraz dahafazla

fikir sahibi oldum." (2)

"Grup sinerjisinin problemi çözme sürecinde önemli olduğunu söyleyebilirim."

"Paylaşımin olması."

"Bana etkin teknikler üretebilirim inancını kazandırd1."

"Vakaları daha dikkatli ve sabrrla incelemek gerektiğini öğretmesi."

Sizce, eğitimin hangi yönü geliştirilmeli?

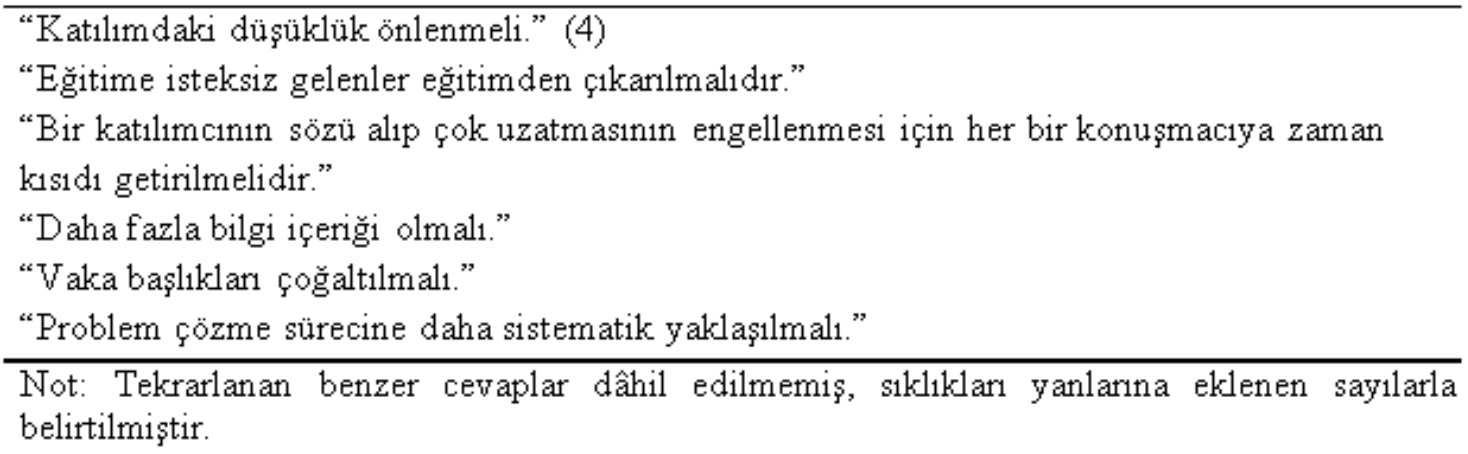




\section{TARTISMA}

Vaka tabanlı çıkarsama yaklaşımıyla çalışanlar tecrübelerinden faydalanarak karşılaştı ̆̆ problemleri daha rahat çözebilmektedir. Ayrıca, yeni problemlere bu mantık 1şı̆̆ında yaklaşabilmektedir ve potansiyel hatalardan kaçınabilmektedir. Giderek çoğalan yaşlı nüfusunun talebiyle doğru orantılı olarak arz edilen yaşlı bakım kuruluşları ve huzurevleri gibi örgütlerde vaka tabanlı çıkarsamayla birlikte problemler daha etkin çözülebilir ve daha kaliteli hizmetler sağlanabilir. Çünkü bu kurumların kendine özgü özelliklerinin eklenmesiyle, karşılaşılan problemler de kısmen bu kurumların karakteristiğine özgün olabilmektedir. Böylece kurumun hafizasına yerleşen vakaların 1şı̆̆ııda, kurumun kendisine özgün problemlerle daha kolay baş edilebilir.

Önceden de belirtildiği gibi İstanbul'da bulunan büyük bir huzurevi yerleşkesinde çalışan birim sorumlularına, vaka tabanlı çıkarsamanın problem çözme yönteminin uygulandığı bir eğitim verilmiş; böylece, bu yöneticilerin problem çözme becerilerinin geliştirilmesi amaçlanmıştır. Bu amaç doğrultusunda diğer benzer vaka tabanlı çıkarsama eğitimlerine ek olarak, katılımcı odaklılı̆̆ arttırılmış, vakalar katılımcıların yaşadığı vakaların diğer katılımcılara yeni bir vakaymış gibi sunulmasıyla aşinalaştırılmıştır. Çalışmanın etkililiği ise problem çözme becerilerinin eğitim öncesi ve sonrası ölçülmesi ve katılımcıların değerlendirmelerinin elde edilmesiyle anlaşılmaya çalışılmıştır.

Yapılan yarı deneysel çalışmanın ön-test ve son-test verilerinin analizleri sonucunda hedeflenen farka ulaşılamamıştır. Eğitim sonunda katılımcılardaki problem çözme becerileri eğitim başına göre önemli ölçüde değişmemiştir. Ancak, katılımcıların eğitimi değerlendirmeleri göz önüne alındiğında, bu eğitimin oldukça dikkat çektiği ve beğenildiği anlaşılmıştır. Katılımcıların büyük bir çoğunluğu eğitimin kullanışlı, pratiğe dönük, bakış açısını genişleten ve önerilebilir olduğunu düşünmüştür. Benzer şekilde, işbirliği içerisinde problemlerin çözülmesi ve bu esnada farklı fikirlerin telaffuzu katılımcıların eğitimi faydalı bulmasını sağlamıştır. Ancak, bazı katılımcıların eğitimin başından sonuna dek devamlılık göstermemesi, devamlılığı bulunan katılımcıları rahatsız etmiş ve bu durum eğitimin en çok geliştirilmesi gereken yönü olarak vurgulanmıştır.

Eğitimde uygulanan problem çözme becerileri ölçeğinin ön-test ve son-test sonuçları incelendiğinde, iki testin arasında önemli bir fark bulunamamıştır. $\mathrm{Bu}$ durum bazı çalışmaların sonuçlarıyla çatışmaktadır. Örneğin, DeMarco ve arkadaşlarına göre (2002), vaka tabanlı çıkarsama öğretisi kişilerin problem çözmede kendilerine olan güvenlerini arttırmaktadır. Ancak bu çalışmada problem çözme becerileri ölçeğinin alt boyutu olan kendine güvenme'de ön-test ve son-test arasında bir fark bulunamamıştır. Ancak dikkat edilmesi gereken diğer bir nokta ise, iki testinde ortalamalarının çok yüksek olmasıdır. Örneğin, hem ön-test hem son-test esnasında katılımcılarda sosyal arzulanabilirlik duygusu (Edwards, 1957) oluşmuş olabilir. Bundan dolayı da testin neyi ölçtüğünü tahmin ederek kendilerini iyi göstermeye çalışmış olabilirler. Bunun yanında, ön-testte verdikleri cevapları hatırlamış ve tutarlılık göstermeye çalışmış da olabilirler. Katılımcılardan elde edilen geri bildirimler incelendiğinde eğitimin problem çözme süreçlerine dair farkındalıklarını etkilediği anlaşılabilir. Bu farkındalıktan dolayı, katılımcılar ölçek sorularını daha bilgili ve gerçek potansiyellerini daha çok dikkate alarak doldurmuş olabilirler. Nitekim, Krockenberger, Bosward ve Canfield'e göre (2007), vaka tabanlı çıkarsama eğitimi eleştirel düşünmeyi arttırmaktadır; bu durumun etkisi son-testte ortaya çıkmış olabilir. Olumlu geri bildirimlerin de yüksek derecede olmasına rağmen test sonuçlarının benzer bulgular göstermemesi bu durumun oluşabilme ihtimalini güçlendirmektedir.

Geri bildirimler dikkate alındığında, katılımcıların eğitimi kullanışlı, pratiğe dönük, bakış açısını genişleten ve önerilebilir bir eğitim olduğunu düşünmesi ise geçmiş çalışmalarla tutarlılık göstermektedir (bknz. Struck \& Teasdale, 2008; Chan vd., 2008; Schwartz vd., 1994; Dochy vd., 2003; Stjernquist \& Crang-Svalenius, 2007). Bu durum, çalışmaların etkili değerlendirilmesi için nitel verilerin de elde edilmesinin önemini ortaya koymaktadır. Tüm bunların yanında, bu çalışmada not edilmesi gereken önemli bir nokta çalışmanın bir kontrol grubunun olmamasidır. Bundan dolayı çalışmadan elde edilen olumlu sonuçlar sadece bu eğitime bağlanamayabilir, belki de kurumda eğitimlerin çok sık yapılmamasından dolayı, katılımcılarda kendileriyle ilgilenildiği duygusu oluşmuş ve bu duygudan dolayı olumlu geri bildirimler artmış olabilir. Yine de, katılımcıların tutumlarının pozitif yönde etkilendiği rahatça söylenebilir.

$\mathrm{Bu}$ çalışmanın diğer önemli bir noktası ise eğitim esnasında katılımcıların işbirliği içinde vakaları değerlendirip çözüm bulmasına yardımcı olmaktır. Lischner'e (2007) ve Evensen ve Hmelo-Silver'a göre (2000), eğitimlerde işbirliği metodunun kullanılması katılımcıların konuya olan ilgisini arttırmaktadır. Dolayısıyla, katılımcıların farklı bakış açıları hakkındaki olumlu geri bildirimleri 
katılımcıların işbirliği yönteminden etkilenilmesinden de kaynaklanabilir. $\mathrm{Bu}$ işbirliğinin getirdiği ortak çalışabilme fikrinin kurum içinde eğitim sonrası başka projelerde tekrar hayata geçmesine katkıda bulunacağı tahmin edilmektedir.

Kurumlarda bulunan vaka havuzu gelecekte karşılaşılabilecek problemlerin çözümünde etkin bir kaynak olarak kullanılabilir. $\mathrm{Bu}$ çalışmanın bu duruma en büyük katkılarından birisi de, kurumda çalışan birim sorumlularının hafızalarında yer alan vakaların toplanması, incelenmesi ve yeni çözümlerle zenginleştirilmesidir. Bundan dolayı, eğitimler sonunda elde edilecek vakaların ve çözüm alternatiflerinin yazıya dökülüp kurumun vaka havuzu adı verilen deposunda saklanması, kurum tarafından üretilmiş bir bilgi kaynağına ve bilgi tasarrufuna aracılık etmiş olur. Her yılın sonunda buna benzer bir eğitim düzenlenip, elde edilen verilerin depoda saklanması örgüt içinde bir rutin haline getirilebilir.

Sonuç olarak, vaka tabanlı çıkarsama öğrenme modeli katılımcıların geri bildirimlerine göre problem çözme becerileri üzerinde etkili bulunmuştur. Ancak yine de kontrol gurubu bulundurulan, daha bilgi içerikli bir seansında eklendiği ve devamlılığın daha etkin sağlandığ çalışmalarda daha net sonuçlar elde edileceği öngörülmektedir. Özellikle, yaşlı nüfusa hizmet eden kuruluşlarda vaka havuzunun oluşturulması ve yöneticilerine bu tarz çıkarsamanın öğretilmesi problemlerin çözülmesinde hı ve verimlilik kazandırabilir.

\section{KAYNAKÇA}

Aamodt, A., \& Plaza, E. (1994). Case-based reasoning: Foundational issues, methodological variations, and system approaches. AI Communications, 7(1), 39-59.

Anderson, J.R. (1993). Problem solving and learning. American Psychologist, 48(1), 35.

Anderson, S.M. \& Helberg, S.B. (2007). Chart-based, case-based learning. South Dakota Medicine: The Journal of the South Dakota State Medical Association, 60(10), 391-393.

Barrows, H.S. (1994). Practice-based Learning: Problem-based Learning Applied to Medical Education. Southern Illinois University, School of Medicine, PO Box 19230, Springfield, IL 627949230 .

Barrows, H.S. \& Tamblyn, R.M. (1980). Problem-based learning: An approach to medical education. Springer Publishing Company.

Chan, W.P. Hsu, C.Y. \& Hong, C.Y. (2008). Innovative "Case-Based Integrated Teaching" in an undergraduate medical curriculum: Development and teachers' and students' responses. Annals Academy of Medicine Singapore, 37(11), 952.

DeMarco, R., Hayward, L. \& Lynch, M. (2002). Nursing students' experiences with and strategic approaches to case-based instruction: a replication and comparison study between two disciplines. Journal of Nursing Education, 41(4), 165-174.

Dochy, F., Segers, M., Van den Bossche, P. \& Gijbels, D. (2003). Effects of problem-based learning: A metaanalysis. Learning and Instruction, 13(5), 533-568.

Domke, H.R., \& Murphy, J.C. (1959). Training nursing home administrators. Public Health Reports, 74(11), 995.

Edwards, A.L. (1957). The social desirability variable in personality assessment and research. Ft Worth, TX, US: Dryden Press.

Evensen, D.H. \& Hmelo-Silver, C.E. (2000). Problembased learning: A research perspective on learning interactions. New York: Routledge.

Flood, A.B. (1994). The impact of organizational and managerial factors on the quality of care in health care organizations. Medical Care Research and Review, 51(4), 381-428.

Flood, A.B., Zinn, J., Shortell, S. \& Scott, W.R. (2000). Organizational performance: Managing for efficiency and effectiveness. Health Care Management: Organization Design and Behavior, 4th ed. Albany, NY: Delmar Thomson Learning. 
Gagné, R.M. (1980). Learnable aspects of problem solving. Educational Psychologist, 15(2), 84-92.

Hakkarainen, P., Saarelainen, T. \& Ruokamo, H. (2007). Towards meaningful learning through digital video supported, case based teaching. Australasian Journal of Educational Technology, 23(1), 87-109.

Hansen, J.T. \& Krackov, S.K. (1994). The use of small group case-based exercises in human gross anatomy: A method for introducing active learning in a traditional course format. Clinical Anatomy, 7(6), 357-366.

Heppner, P.P. \& Peterson, C.H. 1982. The development and implications of a personal-problem solving inventory. Journal of Counseling Psychology, 29, 6675 .

Hofmann, P.B. (1977). The CEO as innovator and catalyst in resources management. Hospital Progress, 58(10), 86-87.

Holton, E.F., \& Swanson, R.A. (1998). The adult learner. Houston, Texas: Gulf Publishing Company.

Hornby, A.S. (2000). Oxford advanced learner's dictionary of current English. S. Wehmeier (Ed.). Cornelsen \& Oxford.

Jonassen, D.H. (2000). Toward a design theory of problem solving. Educational Technology Research and Development, 48(4), 63-85.

Karataş, H. (2011). Üniversite Ö̈̆rencilerinin Epistemolojik Inançları, Öğrenme Yaklaşımları ve Problem Çözme Becerilerinin Akademik Motivasyonu Yordama Gücü (Yayımlanmamış doktora tezi). Yıldız Teknik Üniversitesi/Sosyal Bilimler Enstitüsü, İstanbul.

Kolodner, J.L. (1992). An introduction to case-based reasoning. Artificial Intelligence Review, 6(1), 3-34.

Krockenberger, M.B., Bosward, K.L. \& Canfield, P.J. (2007). Integrated case-based applied pathology (icap): a diagnostic-approach model for the learning and teaching of veterinary pathology. Journal of Veterinary Medical Education, 34(4), 396-408.

Lischner, R. (2007). Collaborative Learning Lite. Erişim http://www.tempest-sw.com/collab.html

Mayo, J.A. (2002). Case-based instruction: A technique for increasing conceptual application in introductory psychology. Journal of Constructivist Psychology, 15(1), 65-74.

Miller, R.H. \& Luft, H.S. (1994). Managed care plan performance since 1980: a literature analysis. JAMA, 271(19), 1512-1519.

Rybarczyk, B.J., Baines, A.T., McVey, M., Thompson, J. T. \& Wilkins, H. (2007). A case-based approach increases student learning outcomes and comprehension of cellular respiration concepts. Biochemistry and Molecular Biology Education, 35(3), 181-186.

Şahin, N., Şahin, N.H. \& Heppner, P.P. (1993). Psychometric properties of the problem solving inventory in a group of Turkish university students, Cognitive Therapy and Research, 4(17), 379-396.

Schwartz, P.L., Egan, A.G. \& Heath, C.J. (1994). Students' perceptions of course outcomes and learning styles in case-based courses in a traditional medical school. Academic Medicine, 69(6), 507.

Srinivasan, M., Wilkes, M., Stevenson, F., Nguyen, T. \& Slavin, S. (2007). Comparing problem-based learning with case-based learning: Effects of a major curricular shift at two institutions. Academic Medicine, 82(1), 74-82.

Stewart, S.R. \& Gonzalez, L.S. (2006). Instruction in professional issues using a cooperative learning, case study approach. Communication Disorders Quarterly, 27(3), 159-172.

Stjernquist, M. \& Crang-Svalenius, E. (2007). Problem based learning and the case method--medical students change preferences during clerkship. Medical Teacher, 29(8), 814-820.

Street, K.N., Eaton, N., Clarke, B., Ellis, M., Young, P. M., Hunt, L. \& Emond, A. (2007). Child disability case studies: an inter-professional learning opportunity for medical students and pediatric nursing students. Medical Education, 41(8), 771-780.

Struck, B.D. \& Teasdale, T.A. (2008). Development and evaluation, of a longitudinal Case-Based Learning (CBL) experience for a Geriatric Medicine rotation. Gerontology \& Geriatrics Education, 28(3), 105-114.

Sturdy, S. (2007). Scientific method for medical practitioners: the case method of teaching pathology in early twentieth-century Edinburgh. Bulletin of the History of Medicine, 81(4), 760-792.

Sutyak, J.P., Lebeau, R.B., Spotnitz, A.J., O'Donnell, A.M. \& Mehne, P.R. (1996). Role of case structure and prior experience in a case-based surgical clerkship. The American Journal of Surgery, 172(3), 286-290.

Thistlethwaite, J.E., Davies, D., Ekeocha, S., Kidd, J.M., MacDougall, C., Matthews, P. \& Clay, D. (2012). The effectiveness of case-based learning in health professional education. A BEME systematic review: BEME Guide No. 23. Medical Teacher, 34(6), 421444. 
Thorley, L., Gregory, R.D. \& Gregory, R. (Eds.). (1994). Using group-based learning in higher education. UK: Psychology Press. 